\title{
Is a successful research laboratory possible with undergraduate students alone?
}

\author{
Roger V. Gonzalez, Juan Lopez, and Paul Leiffer \\ LeTourneau Univer sity
}

\section{Abstract}

Developing a successful research laboratory with qualified graduate students is a demanding venture. Trying to accomplish this with undergraduate students alone, given the demanding academic load and steep research learning curve is daunting. Nevertheless, during the past eight years the Biomedical Engineering Faculty at LeTourneau University have managed to develop a successful undergraduate research program and secure multiple external funding sources. Laboratory research has been intricately woven into the undergraduate engineering curriculum and is a key component of the teaching-learning engineering environment. The objective is to use undergraduate research to teach engineering skills such as research methodology, design, development, manufacturability, testing, and implementation. These skills are necessary for successful engineers to be proficient, regardless of specialization. Primarily, the success of our research utilizing only undergraduate students has come from the project management methodology implemented to stimulate success both in the research endeavors and for the students who participate. The research process involves interdisciplinary undergraduate research teams with a minimum of one-year student participation. The research team structure is based on a business model of modular components. Students and professors are both an integral part of this modular structure, with students involved at various levels, including management. Each component is treated as an individual hierarchy with its own set of goals, yet responsible to the overall management structure and research objectives. The challenges that are naturally inherent to using only undergraduate students for research are addressed in this paper via a description of both the team structure and multi-level student participation. Dissemination of results is a critical portion of the research process, with requirements for external publication an integral part of the objectives set for the team. Success of our undergraduate research model has been evident not only by securing external funding but also from external publications, achieved educational outcomes, high student satisfaction, and a considerable level of undergraduate students pursuing graduate engineering education.

\section{Introduction}

Success as an engineering professor involves much more than effective classroom teaching. At a minimum, it involves effective interaction with students, pedagogy, and university service. Yet at most institutions, this is not enough. Scholarly work in the form of research is critically evaluated as a means of assessing a professor's effectiveness. The traditional method has always been to recruit graduate students as research assistants to perform the research as part of their larger graduate educational objectives. The dilemma occurs when a professor is asked to develop 
a research program when the institution does not have a graduate program in the professor's given discipline. While this is possible, having only undergraduate students to provide the needed talent and resources makes this a much more challenging endeavor. It has been demonstrated that an undergraduate research program enhances undergraduate education [1] as well as increases the perceived value of the educational curriculum [2]. In addition, research that is project based increases team learning, leadership, communication skills, integration of knowledge, and more [3], while also increasing the occurrence of undergraduates pursuing a graduate degree [4]. Therefore, how can a professor develop a research laboratory, much less a successful one, with a very limited and short-lived talent pool? One could argue that some undergraduate students can perform effective research, however personal mentoring and "bringing them up to speed" requires a substantial amount of time investment - and if this is done with upper-class students, the attrition rate due to graduation is very punishing to multiyear research projects.

Most of our research projects are within Biomedical Engineering as we currently have two ongoing multi-year research projects. The first involves the study of the "Intelligent Prosthetic Arm" which seeks to understand complex motor control sequencing in multi-joint movements as well as how such movements may be better understood and controlled via EMG signals. The second is the study of inter-segmental forces at the human knee pre and post ACL injury. Specifically, we seek to validate a complex musculoskeletal computational model via experimental studies of cadaveric knees under time-varying muscle loads.

Regardless of the research topic, the principles developed in this paper cross disciplinary boundaries. Thus, the objective of this paper is to elaborate on our experience and the methodology that we have found to be effective in developing a successful undergraduate research laboratory and research program at a strictly undergraduate engineering institution.

\section{Methods}

We have found that a minimum of three strategic objectives, as stated below, are needed to implement an undergraduate research program with no support from graduate students.

\section{Supportive Educational Curriculum}

First, research must be woven into the broader educational curriculum - at a minimum during the senior year. This is affected by how the department or division views the role of research in the educational process. If it views it positively, how does it specifically seek to encourage it and support its endeavors? At LeTourneau University we involve research as part of our twosemester capstone senior design sequence. While not all of our students are required to have a research project, several students do participate in funded research projects - especially those who may be considering graduate school. As an added bonus, the engineering program at LeTourneau University allows a student to take a 3-hour technical elective during his/her junior year to participate as a "junior member" of the senior research team. This junior technical elective is spread throughout the entire junior year and involves a significant commitment of the student. In one particular major, Biomedical Engineering, the junior research experience is required as part of the curriculum. Since the Biomedical Engineering sequence is much more 
research oriented, the two-year research involvement is critical not only to the students' education but also to supporting the biomedical research program at large. Of particular importance, though, is that all research teams are multi-disciplinary and have members from at least the biomedical, electrical, and mechanical engineering disciplines. While this diversity of disciplines enriches the research process, it can also pose significant problems if not managed properly. It is also critical that the senior level course includes significant design and development as well as a research component. In addition to the senior level courses, LeTourneau University's School of Engineering successfully incorporates design, development, teamwork, report-generation, and presentation skills in many of the lower-level courses. It is typical for engineering students to have participated in at least one major design and development project every year of their engineering studies leading up to the senior year. This preparation and emphasis on class projects and designs has been very successful in preparing students to be successful in and ready for the senior year research experience.

\section{Teaching-Learning Research Environment}

Second, the teaching-learning aspects of the research are critical. For the past 8 years, sizes of the overall research teams have ranged from 8 to 25 students. While the teams are broken down into sub-groups, it is obvious that one advisor cannot play the role of mentoring each of these students individually. Thus, the approach to teaching and mentoring is important. Our method has been to adopt a Team Lead structure. This structure, while having many advantages (to be discussed in the third section, below), gives the research advisor (i.e. Principal Investigator or PI) a reasonable number ( 3 to 5) of student leaders to mentor and teach. The team leads then provide a modified version of mentoring to their fellow classmates in their sub-group on the tasks required. Examples of sub-groups in a recent project include: Mechanical, Experimental, Computational, and Electrical. An important point is that each team member is encouraged and has the opportunity to meet with the PI as needed based on his/her individual needs and tasks assigned, while removing the need for a day-to-day interaction and monitoring for the minutia of research.

A secondary critical aspect of the teaching-learning component is that junior team members are mentored by senior team members in specific areas of the research. During the junior year these students contribute to that specific research area so as to "learn the ropes," then, typically in their senior year, to lead that specific sub-group. This student-led mentoring is a very important developmental process in the senior team members who participate. Experience has shown that teaching and mentoring a junior student can significantly increase the quality of knowledge and ability in the mentoring senior student through this process alone. A senior cannot teach that which he/she do not know or understand - thus requiring the student to be thoroughly familiar with the research. This mentoring also allows the junior student to become a future senior student of increased quality and knowledge.

A significant part of the mentoring process for the PI is to infuse in his leadership team the love for research - that is, the love to discover. Once this is taken to heart, the rest is secondary. Some disciplines, such as biomedical engineering, develop an early sense of self-inquiry through a series of self-discovery laboratory exercises in the engineering curriculum. Other aspects of the mentoring process include learning good design, development, manufacturability, testing, and implementation principles and practices. Depending on the tasks and principal engineering 
disciplines of each sub-group, certain items are emphasized more than others. Yet all teams are informed that they must consider aspects related to other teams in their engineering process.

It is the responsibility of the PI is to keep in mind that lower-level students will need to replace the graduating seniors. Therefore, students who show promise early in their engineering studies should be approached about participating in the laboratory. With casting a broad net, some students will respond positively and will become the future leaders of the team, thus keeping students in the research pipeline so as to not be left without a qualified team upon seniors graduating.

\section{Effective Management}

Third, and probably the most important to overall success of the undergraduate research team concept, is how both the team and project are managed. The management structure used is one taken from a corporate business model as experienced by the lead author during his industrial engineering career. This model provides a good learning environment for students as they receive exposure to a traditional business model they may experience in a company upon graduation.

The management structure developed is directly taken from business where the Principal Investigator (PI) is the CEO, and the following positions are assigned to students: Project Manager (PM), Engineering Leads (EL), and Individual Contributors (IC). Figure 1 shows the structure used for the 2003-04 academic year in our Intelligent Prosthetic Arm project. This is a typical organizational chart and is determined within the first week of the fall semester by the PI with input from the incoming previous year's members.

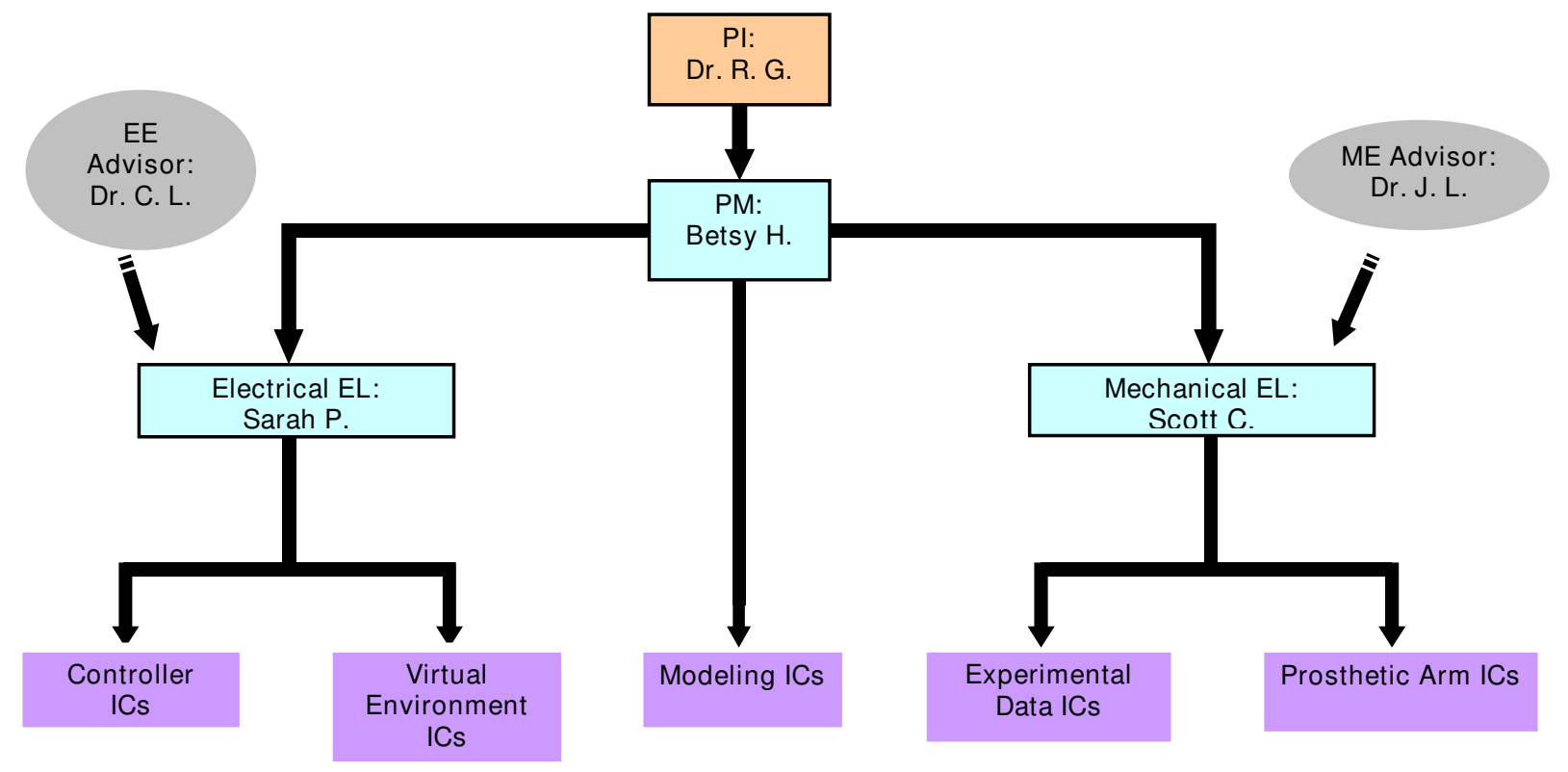

Figure 1 - Team Organizational Chart (Team Structure) based on a modular component structure. 
As also seen in Figure 1, a modular team structure is used to describe the overall scope of the project as well as the assignment of students to the EL and IC to a sub-group. This team structure allows clear lines of distinction between various responsibilities and the order of how information and responsibility flows within the team. The PM is responsible for the overall management of the project and team while still having a specific technical responsibility on the team. The selection of the PM is an extremely important decision. This person must not only have developed a love for discovery, but have had previous experience on the team so as to understand the overall goals of the project. This person should possess leadership skills and have the respect of their peers. Almost always, the selected PM comes from students who participated as junior members of the team and performed well. The PI selects the PM with input from the likely ELs, who themselves are usually selected from the well-performing juniors on the team. The PI's role as a professor and research advisor will be the team's CEO allowing long-term continuance of background knowledge on the abilities of students for the PM and EL positions,

Accountability is what gives strength to this management structure. Students must realize that they are making a significant year-long commitment to the overall success of the team and their team-mates. At LeTourneau University the capstone senior design sequence has developed a reputation of engulfing a student's senior year. This attitude is an appropriate one as it puts the research experience in a much better perspective. The student attitude should be: "this is not a course - it is an experience." We've noted that if a student involved on a research team is simply "counting his/her hours to graduation" then the experience is short changed and the components that that person is involved with typically suffer.

With the management structure established, accountability then becomes a way to create an effective team. How can members on the team be made accountable? Accountability is established using the Gantt chart, Documentation, and Quality Assessment.

Gantt Chart: A Gantt chart is developed by the leadership team, which consists of the PI, PM, and ELs. After a thorough assessment of the overall objectives for the year, as determined by the PI, the PM works closely with the ELs and PI to correctly assess the individual components of the project based on the organizational chart previously developed. A Gantt chart encompasses three critical items: (1) Milestones - what are the major tasks for the team? (2) Deadlines - when will these milestones be achieved? (3) Responsibility - who is the person responsible for each milestone and sub-tasks? We believe it is important to have individual responsibility even on multi-person tasks. Figure 2 shows a significantly scaled down version of a typical Gantt chart.

Documentation: If the team is going to pass forward their knowledge and experience to future teams, a documentation plan is needed. We are still in development of this item. Documentation and the quality of the documentation is time consuming as well as difficult to convey. We have three levels of documentation: (1) Laboratory Notebook - we have developed a preliminary version of an electronic laboratory notebook using Microsoft Access so students can document daily activities, problems, solutions, hours, misc. Figure 3 shows an example of the data entry screen developed for our laboratory. (2) General Documentation - this is the larger view of the project as required by the senior design class. This is typically several hundred pages with an executive summary; each sub-group has a section, and contains needed appendices with drawings, pertinent literature articles, etc. (3) Dissemination - our previous success with peer- 
reviewed publications (conferences or journals) by one or two people on each research team has led to the expansion of the requirement, and now each sub-group is required to publish its results at a relevant conference. Occasionally, the results are then gathered together in such a way so as to submit an article to a referred journal.

Quality Assessment: Excellence is required of all students participating. It is not enough to meet deadlines, write reports, and gather data. The quality of the work is assessed and impacts the assignment of the course grade. Through this assessment that rewards and repercussions are given. Admittedly, the ultimate incentive is the assignment of an excellent course grade. Yet, other rewards and repercussions can be given. For example, as a reward, students are sometimes invited to social gatherings sponsored by the PI and occasionally a pizza is brought to the laboratory for a spontaneous party during a laboratory meeting or experiment. One time, the team was taken to a theme park for the day - sponsored by the PI. All of these activities help build a unified team spirit and camaraderie. As a form of negative reinforcement, students in leadership have been removed from their responsibilities and been made individual contributors while the leadership position is given to a team member who has been found to be responsive to his/her duties. Individual contributors in the past have had to spend significant time with the PI (one-on-one) explaining the caliber of their work and having to repeat his/her work until it meets excellent standards. Both of these are alternative forms of reinforcement that foster accountability and excellence from the overall team. However, excellence flows from the top of the model down. If the PI and the PM are not performing in a manner that demonstrates excellence, it will be tough to demand this from the ELs and ICs on the team.

Typically about $80 \%$ of the senior design course grade is determined from the project performance. Appendix A shows the breakdown of the project grade as given to the students. Please note that because multi-disciplinary teams are on the project, the amount the project counts toward each discipline can vary. Final grade distribution has ranged from A to D with the majority earning a B or higher. This high grade average is due to the fact that the students involved in the project are typically very highly motivated and take a serious view of the responsibilities given to them.

\section{Results}

While the process still continues to mature, we would point toward various measurable indicators of research success such as external funding, external publications, realized educational outcomes, and student satisfaction.

Our laboratory has secured three federally funded projects totaling over $\$ 700,000$. These funds have allowed the development of a modern experimental laboratory in engineering biomechanics involving over 100 undergraduate engineering students over the past eight years of the program performing research during their junior and senior years. More than 30 publications have appeared in peer reviewed scientific conferences (e.g. [5-10]), all with an undergraduate student as the lead author (ASME, American Society of Biomechanics, Engineering in Medicine \& Biology, etc). Over 15 students who have graduated within the last three years are pursuing PhD's at various top graduate schools. 
A significant level of satisfaction of how the research experience has contributed to the overall education of individual students was assessed by our Office of Sponsor Programs. Of the students who participated in the research project over the last two years, results ("strongly agree" and "agree") indicate that the project benefited their academic development (92\%), provided real world experience (78\%), provided adequate professor supervision (84\%), influenced them to continue toward an advanced degree (67\%), had a positive impact on educational experience (94\%), and that they would recommend other students work on research projects $(92 \%)$.

A word of caution: faculty desiring to undertake research with undergraduates need to understand is that it takes large amounts of planning and a time commitment at least twice the normal amount that it would take with graduate students. 


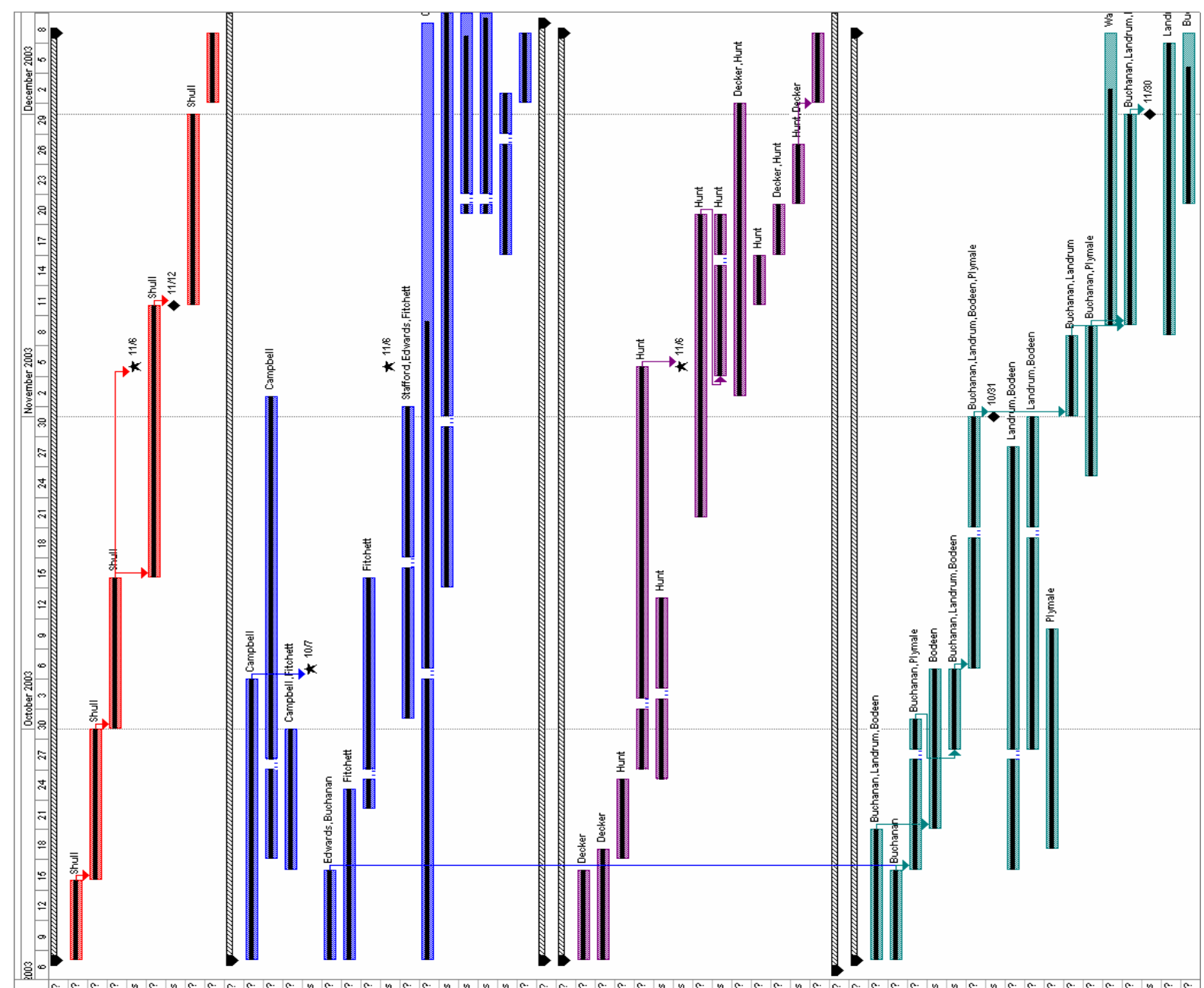

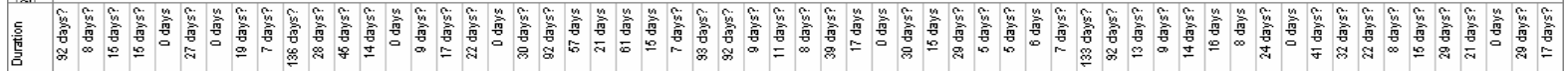

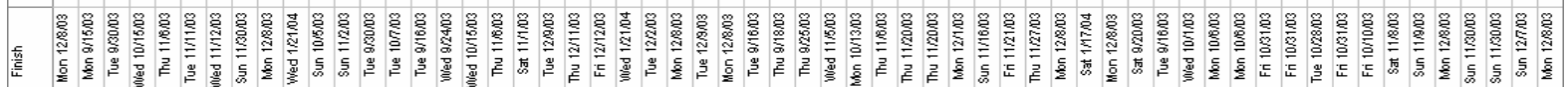

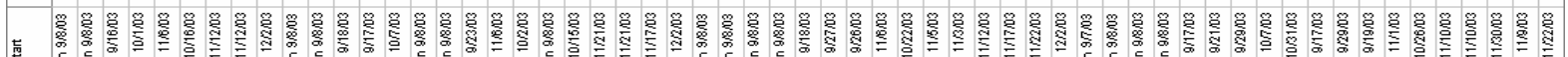

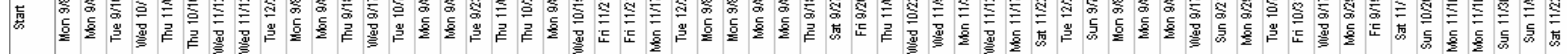

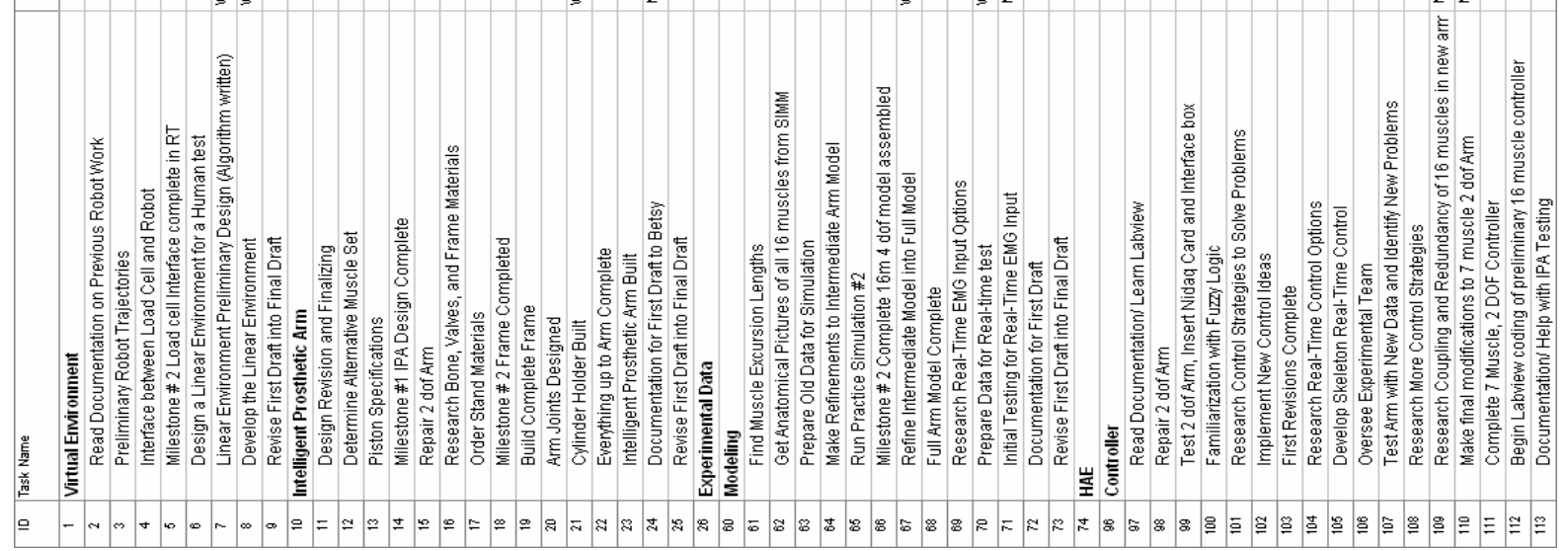

Figure 2 - Gantt chart developed during the first couple of weeks of the Fall Semester which indicates tasks, deadlines, responsible party, and interdependencies. 


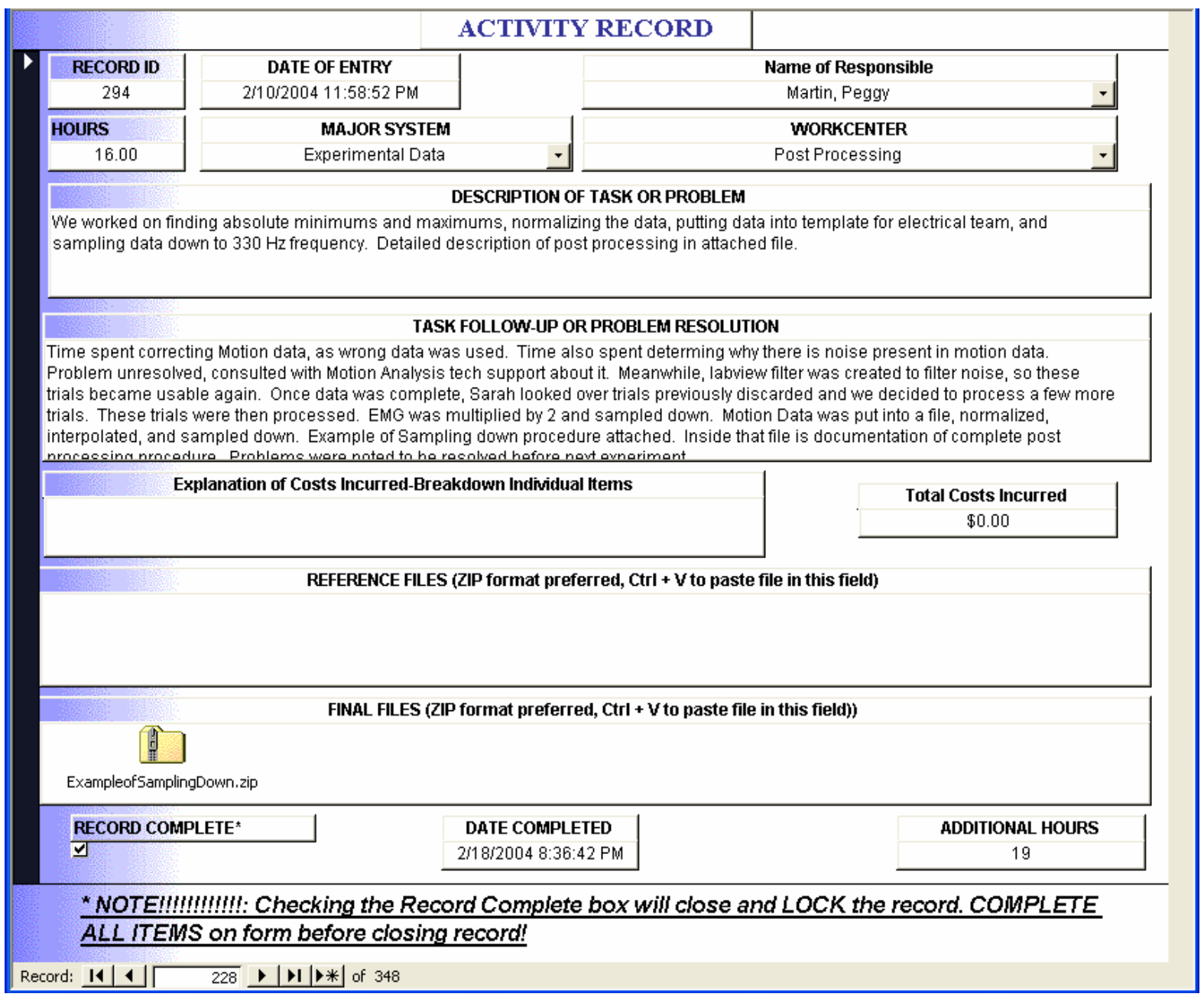

Figure 3 - Electronic Notebook developed with Microsoft Access for detailed research records.

\section{Conclusions}

Based on our experience, we believe that the above mentioned methodology yields success in areas that an engineering professor/investigator desires to see in a thriving research laboratory: external funding, external publications, student satisfaction, educational impact, and long-term impact. In our opinion the keys to establishing a successful undergraduate research program with undergraduates alone are: (1) Requiring research as a key portion of the educational curriculum; (2) Implementing an effective management structure, (3) Teaching-Learning Experience keeping students in the pipeline learning from one another since no one knows it all, not even the PI. 


\section{References}

[1] Gates, A.Q., Teller, P.J., Bernat, A. Delgado, N., Della-Paina, C.K. Expanding Participation in Undergraduate Research Using the Affinity Group Model. J. of Engineering Education, October, 1999, pp. 409-414.

[2] Zydney, A.L., Bennett, J.S., Shahid, A., and Bauer, K.W. Impact of Undergraduate Research Experience in Engineering. J.of Engineering Education, April, 2002, pp. 151-157.

[3] Luxhoj, J.T., and Hansen, P.H.K. Engineering Curriculum Reform at Aalborg University. J. of Engineering Education, July 1996, pp. 183-186.

[4] Narayanan, R.M. Use of Objective-Based Undergraduate Research Project Experience as a Graduate Student Recruitment Tool, J. of Engineering Education, July 1999, pp. 361-365.

[5] Hunt, B.V., Hunter, A.J., and Gonzalez, R.V. (2004) Determining Leg Dominance: A Quantifiable Approach. Journal of Applied Biomechanics. (Submitted)

[6] Rask, M.R, Barr, R.E., and Gonzalez, R.V. (2003) Genetically-Designed Neural Networks for Error Reduction in an Optimized Biomechanical Model of the Human Elbow Joint Complex. Computer Methods in Biomechanics and Biomedical Engineering (in press).

[7] Hunt, B.V. and Gonzalez, R.V. (2004) Moment arm verification of a computational musculoskeletal arm model. 21st Annual Houston Conference on Biomedical Engineering Research, Houston, TX, Feb, 2004.

[8] Webb, J.D. and Gonzalez, R.V. (2003) A Three Dimensional Forward Dynamic Model of a Human Knee for Determining Ligament Forces. ASME National Congress, Washington, DC, Nov, 2003.

[9] Gardinier, J., and Gonzalez, R.V. (2003) Pronation-Supination Moment Arms in the Human Forearm. ASME Summer Bioengng Conf, Key Biscayne, FL, June, 2003.

[10] Kirkendall, A.L., Lopez, J.M., and Gonzalez, R.V. (2002) A kinematic analysis of an ACL deficient knee. ASME National Congress, New Orleans, LA, Nov, 2002. 1st Place Undergraduate Student Paper Award

\section{Biographical Information}

ROGER V. GONZALEZ, PhD, PE

Dr. Gonzalez is a professor of BME \& ME at LeTourneau University with specialties in Musculoskeletal Biomechanics and Dynamic Systems Modeling; Adjunct Professor in ME at University of Delaware; Texas PE. He earned a BSME from UTEP and a M.S. and Ph.D. in BME and ME, respectively, from UT Austin. He also was NIH-NRSA Post-Doctoral Fellow at Northwestern University Medical School, and the Rehabilitation Institute of Chicago. Email: rogergonzalez@letu.edu.

JUAN M. LOPEZ, E.I.T.

Juan M. Lopez is a Project Engineer with IFS in Tyler, Texas. He has a B.S. in Engineering (2002) from LeTourneau University, where he studied under Dr. R.V. Gonzalez in the BME Research Lab. He is currently a Technical Advisor to the lab, collaborating with Dr. Gonzalez on research, student guidance, and grant-writing. He is preparing to enter a BME Ph.D. program and also complete his PE. Email: juanlopez@sydcom.net

PAUL R. LEIFFER, PhD, PE

Dr. Leiffer is a professor in the School of Engineering and Engineering Technology at LeTourneau University, where he has taught since 1979. He received his M.S. and Ph.D. degrees from Drexel University. Prior to joining the faculty at LeTourneau, he was involved in cardiac cell research at the University of Kansas Medical Center. Email: paulleiffer@letu.edu 
Appendix A

\author{
Biomedical Engineering \\ Senior Design Project Grade Criteria
}

Breakdown of how the Project Grade will be determined:

$30 \%$ Documentation

2 - General Documentation Reports (Fall Semester 25\%; Spring Semester 15\%):

- One due at the end of each Semester

- Each sub-team will receive a grade based on their report. The report grade will be equally weighted between the quality of the entire report and the sub-team report. The final general report will be a compilation that represents the team structure, not an ME \& EE division.

1 - Personal Research Notebook (5\%): required of each team member and to be reviewed during the $7^{\text {th }}$ and $14^{\text {th }}$ week of each Semester. This report should clearly indicate WHAT, WHEN, HOW, WHO, and WHY for aspects of the project this individual participated in. Each notebook should be tabbed so that reference to individual projects can easily be found upon inspection. These may be hand written or computer generated. Yet they will be contained in one notebook as given by the advisor. Team leads will review notebooks and submit them to advisor with comments \& criticisms about the quality of the notebooks for their team members. Project manager will also maintain a notebook that includes all needed laboratory upgrades and maintenance, especially as they relate to computers and computer peripherals.

1 - Scientific Publication (Not required during the Fall Semester; Spring Semester 10\%) (either Journal or Conference Proceeding format as determined by advisor) from each subgroup due by the $12^{\text {th }}$ week of the spring semester. This will be led by the sub-team leader and grade shared among all sub-team members.

20\% Deadlines Achieved

- Determined from Gantt Chart and equally weighted

- Gantt chart must include deadlines for first drafts and final submission of general documentation and the scientific publication.

- The advisor, with input from the team leader and project manager, will have the final assessment of whether a missed deadline was legitimate. If considered legitimate, a new deadline will be established and no penalty will be assessed for the initial missed deadline for that particular task.

$\circ$ The amount of penalty increases as the time from the deadline to accomplished task increases. This will be handled on a case by case basis.

50\% Design, Fabrication, and Performance

- Distribution of this percentage will vary based on team objectives

Notes:

Input from Project Manager / Team Leader on all participates will be sought by the advisor as well as input from individual team members on their team leader / Project Manager. This input will be considered as "performance."

All grades will be assigned to sub-teams and the breakdown of this grade to individual grades will be based on internal assessment within the team such as is done for dynamics projects. 